\title{
Delayed Foreign Body Reaction Caused by Bioabsorbable Plates Used for Maxillofacial Fractures
}

\author{
Hong Bae Jeon, Dong Hee Kang, Ja Hea Gu, Sang Ah Oh \\ Department of Plastic and Reconstructive Surgery, Dankook University Hospital, Dankook University College of Medicine, Cheonan, Korea
}

Background Bioabsorbable plates and screws are commonly used to reduce maxillofacial bones, particularly in pediatric patients because they degrade completely without complications after bone healing. In this study, we encountered eight cases of a delayed foreign body reaction after surgical fixation with bioabsorbable plates and screws.

Methods A total of 234 patients with a maxillofacial fracture underwent surgical treatment from March 2006 to October 2013, in which rigid fixation was achieved with the Inion CPS (Inion, Tampere, Finland) plating system in 173 patients and Rapidsorb (Synthes, West Chester, PA, USA) in 61 patients. Their mean age was 35.2 years (range, 15-84 years). Most patients were stabilized with two- or three-point fixation at the frontozygomatic suture, infraorbital rim, and anterior wall of the maxilla.

Results Complications occurred in eight (3.4\%) of 234 patients, including palpable, fixed masses in six patients and focal swelling in two patients. The period from surgical fixation to the onset of symptoms was 9-23 months. Six patients with a mass underwent secondary surgery for mass removal. The masses contained fibrous tissue with a yellow, grainy, cloudy fluid and remnants of an incompletely degraded bioabsorbable plate and screws. Their histological findings demonstrated a foreign body reaction.

Conclusions Inadequate degradation of bioabsorbable plates caused a delayed inflammatory foreign body reaction requiring secondary surgery. Therefore, it is prudent to consider the possibility of delayed complications when using bioabsorbable plates and surgeons must conduct longer and closer follow-up observations.

Keywords Absorbable implants / Foreign body reaction / Maxillofacial injury
Correspondence: Dong Hee Kang Department of Plastic and Reconstructive Surgery, Dankook University Hospital, Dankook University College of Medicine, 201 Manghyang-ro, Dongnam-gu, Cheonan 31116, Korea Tel: +82-41-550-6477 Fax: +82-41-554-6477 E-mail:dhkcool@daum.net

This article was presented as an E-Poster at the 72nd Congress of the Korean Society of Plastic and Reconstructive Surgeons on November 7-9, 2014 in Seoul, Korea.

No potential conflict of interest relevant to this article was reported.

Received: 31 Mar 2015• Revised: 29 May 2015• Accepted: 1 Jun 2015

pISSN: 2234-6163 • elSSN: 2234-6171 • http://dx.doi.org/10.5999/aps.2016.43.1.40 • Arch Plast Surg 2016;43:40-45

\section{INTRODUCTION}

Metallic plates and screws are commonly used for rigid internal fixation during maxillofacial surgery [1]. However, metallic implants have problems, such as visibility on radiography, palpabil- ity, bone erosion and growth restrictions, thermal sensitivity, and the need for removal $[2,3]$. Various bioabsorbable materials have been developed to overcome these disadvantages of metallic implants [4]. Ideally, bioabsorbable plates are sufficiently rigid and biocompatible, provide sufficient stability to allow bone 
healing, and are eliminated completely after osteosynthesis without a foreign body reaction $[5,6]$. They do not require any secondary operation for removal due to their characteristics. Thus, bioabsorbable plates and screws are commonly used to reduce maxillofacial bones, particularly in pediatric patients [7]. Polyglycolic acid (PGA) and polylactic acid (PLA) are the polymers used most widely to manufacture bioabsorbable plates and screws $[5,8]$. Plate degradation properties and rates vary depending on the ratio of lactic acid isomers or glycolic acid. If the bioabsorbable plates fail to degrade completely or undergo polymeric breakdown beyond the maximum metabolic clearance rate, the remnant material can become a nidus for an inflammatory foreign body reaction [8-10]. Copolymers such as polylactic-co-glycolic acid are often used commercially because these complications are almost always associated with homopolymers $[8,10,11]$. Many studies have reported the efficacy and clinical utility of bioabsorbable plates, but few reports are available on complications associated with the plates, resulting from inadequate degradation of the plates [12,13]. Between March 2005 and October 2013, we encountered eight cases of a delayed foreign body reaction after surgical fixation with bioabsorbable plates and screws. We report these cases with a review of the literature.

\section{METHODS}

The medical records of 372 patients who underwent surgical treatment with metal plates $(\mathrm{n}=138)$, bioabsorbable plates $(\mathrm{n}=176)$, or both $(\mathrm{n}=58)$ for a maxillofacial fracture between March 2006 and October 2013 were reviewed retrospectively. The data included fracture patterns, fixation methods/materials, and any complications. A total of 234 patients who were treated using bioabsorbable plates (186 men and 48 women; age, 15-84 years; mean age, 35.2 years) were included in our study. They were diagnosed with a zygomaticomaxillary complex fracture $(n=146)$, maxilla fracture $(n=57)$, nasoethmoid orbital fracture $(n=20)$, or a LeFort fracture $(n=11)$. Rigid fixation was achieved with the Inion CPS (Inion, Tampere, Finland) plating system in 173 patients and Rapidsorb (Synthes, West Chester, PA, USA) in 61 patients (Table 1). Metal plates were used with bioabsorbable plates in 58 of 234 patients. Patients were selected to receive bioabsorbable fixation on the basis of the degree of bony displacement, fracture pattern or location, and patient age. Patients with an isolated, noncomminuted, minimally displaced fracture were good candidates for bioabsorbable fixation. However, biodegradable plates were regarded as the most appropriate in young patients irrespective of the fracture type. All fractures were approached in the standard fash-

\section{Table 1. Patient demographics}

\begin{tabular}{|lc|}
\hline Characteristic & Number (\%) \\
\hline Total & 234 \\
Male & $186(79.5)$ \\
Female & $48(20.5)$ \\
Age/Range (yr) & $35.2 / 15-84$ \\
Diagnosis & \\
ZMC fracture & $146(62.4)$ \\
Maxilla fracture & $57(24.4)$ \\
NEO fracture & $20(8.5)$ \\
LeFort fracture & $11(4.7)$ \\
Material & \\
Inion CPS & $173(73.9)$ \\
Rapidsorb & $61(26.1)$ \\
Complications & \\
Palpable, fixed mass & $6(2.5)$ \\
Focal swelling & $2(0.9)$ \\
Total & $8(3.4)$ \\
\hline ZMC, zygomaticomaxillary complex; NEO, nasoethmoid orbital. \\
\hline
\end{tabular}

ion, and most patients were stabilized with a two- or three-point fixation at the frontozygomatic suture $(2.0-\mathrm{mm}$ plate and $7-\mathrm{mm}$ screws), infraorbital rim (1.5-mm plate and 6-mm screws), and anterior wall of the maxilla (1.5-mm mesh plate and 4-mm screws). In the statistical evaluation, a logistic regression analysis was used (level of significance, $\mathrm{P}<0.05$ ). Odds ratios were calculated, and $95 \%$ confidence intervals were constructed where appropriate.

\section{RESULTS}

A total of 234 patients achieved satisfactory bone healing with favorable restoration in form and function and no signs of inflammation, such as a heating sensation or tenderness, during the early postoperative period. Complications occurred in eight (3.4\%) of the 234 patients, including palpable, fixed masses in six patients and focal swelling in two patients (Table 1). Six patients were diagnosed with a zygomaticomaxillary complex fracture, and two were diagnosed with a nasoethmoid orbital fracture. Six of them were fixed with Inion CPS plates, and two were fixed with Rapidsorb plates. The period from surgical fixation to the onset of symptoms was 9-23 months. We were determined to perform the operations when the masses formed. Two patients with focal swelling were under observation without surgery for a mean duration of 13 months after fixation. Six patients with a mass underwent secondary surgery for the exploration and removal of the mass at a mean duration of 17.7 months after fixation. The masses developed in the bioabsorbable fixation sites, including the frontozygomatic suture $(\mathrm{n}=3)$, the infraorbital rim $(\mathrm{n}=2)$, or both $(\mathrm{n}=1)$ (Table 2). A surgical skin incision was 
Table 2. Characteristics of the patients with complications

\begin{tabular}{|c|c|c|c|c|c|c|c|c|}
\hline $\begin{array}{c}\text { Patient } \\
\text { no. }\end{array}$ & $\begin{array}{l}\text { Sex/ } \\
\text { Age } \\
\text { (yr) }\end{array}$ & Diagnosis & $\begin{array}{l}\text { Fixation plates } \\
\text { (size, mm) }\end{array}$ & $\begin{array}{c}\text { Onset of } \\
\text { symptom after } \\
\text { surgery (mo) }\end{array}$ & Symptom & Location & Treatment & $\begin{array}{l}\text { Histologic } \\
\text { examination }\end{array}$ \\
\hline 1 & $M / 36$ & ZMC Fx & Rapidsorb (2.0) & 23 & Palpable, fixed mass & Frontozygomatic suture & Operation & Foreign body granuloma \\
\hline 2 & $M / 28$ & ZMC Fx & Inion CPS (2.0) & 17 & Palpable, fixed mass & Frontozygomatic suture & Operation & $\begin{array}{l}\text { Foreign body reaction with } \\
\text { fibrosis }\end{array}$ \\
\hline 3 & $M / 28$ & ZMC Fx & Inion CPS (2.0) & 15 & Palpable, fixed mass & Frontozygomatic suture & Operation & $\begin{array}{l}\text { Foreign body reaction with } \\
\text { fibrosis }\end{array}$ \\
\hline 4 & $\mathrm{M} / 56$ & ZMC Fx & $\begin{array}{l}\text { Inion CPS (2.0) } \\
\text { Inion CPS (1.5) }\end{array}$ & 21 & Palpable, fixed mass & $\begin{array}{l}\text { Frontozygomatic suture } \\
\text { Infraorbital rim }\end{array}$ & Operation & $\begin{array}{l}\text { Foreign body reaction with } \\
\text { fibrosis }\end{array}$ \\
\hline 5 & $\mathrm{M} / 40$ & NEO Fx & Inion CPS (1.5) & 10 & Palpable, fixed mass & Infraorbital rim & Operation & $\begin{array}{l}\text { Foreign body reaction with } \\
\text { fibrosis }\end{array}$ \\
\hline 6 & $M / 49$ & NEO FX & Inion CPS (1.5) & 18 & Palpable, fixed mass & Infraorbital rim & Operation & $\begin{array}{l}\text { Foreign body reaction with } \\
\text { fibrosis }\end{array}$ \\
\hline 7 & $M / 21$ & ZMC Fx & Inion CPS (2.0) & 17 & Focal swelling & Frontozygomatic suture & Observation & No \\
\hline 8 & $\mathrm{~F} / 58$ & ZMC Fx & Rapidsorb (2.0) & 9 & Focal swelling & Frontozygomatic suture & Observation & No \\
\hline
\end{tabular}

Table 3. Odds ratio of patients with and those without a foreign body reaction

\begin{tabular}{|c|c|c|c|c|}
\hline Characteristic & $\begin{array}{l}\text { Patients with } \\
\text { a foreign } \\
\text { body reaction } \\
(n=8)\end{array}$ & $\begin{array}{l}\text { Patients without } \\
\text { a foreign } \\
\text { body reaction } \\
(n=226)\end{array}$ & $\begin{array}{l}\text { Odds } \\
\text { ratio }\end{array}$ & P-value \\
\hline Gender & & & & $0.57^{\mathrm{a})}$ \\
\hline Male & 7 & 179 & 1.84 & \\
\hline Female & 1 & 47 & 0.54 & \\
\hline Material & & & & $0.94^{\text {a) }}$ \\
\hline Inion CPS & 6 & 167 & 1.06 & \\
\hline Rapidsorb & 2 & 59 & 0.94 & \\
\hline
\end{tabular}

a) $<0.05$, significant difference; $P>0.05$, no significant difference.

made along the previous scar. The masses contained fibrous tissue with a yellow, grainy, and cloudy fluid and remnants of incomplete degraded bioabsorbable plates and screws. A connective tissue capsule was seen around the foreign material and was composed of thin collagen fibers with numerous fibroblasts and fibrocytes. Multinucleate giant cells, lymphocytes, and histiocytes were evident. The masses were diagnosed as a foreign body reaction. The tissue culture results were negative in all patients, and the masses did not recur during a 1-year follow-up after recovery. There was no difference in gender and material type causing the foreign body reaction between the patients with and those without a foreign body reaction (Table 3).

\section{Case 1 (patient no. 1 )}

A 36-year-old man visited our clinic to treat a mass on the left frontozygomatic suture. He had fallen 29 months earlier, under alcohol intoxication. The patient had a left zygomaticomaxillary complex fracture, which was fixed with a Rapidsorb 2.0-mm 4-hole plate on the frontozygomatic suture, a 1.5 - $\mathrm{mm} 8$-hole plate on the infraorbital rim, and a bioabsorbable mesh plate on the anterior wall of the maxilla. He suffered from a palpable, fixed mass measuring $1 \mathrm{~cm} \times 2 \mathrm{~cm}$ for 6 months (Fig. 1A). A computed tomography (CT) scan 23 months after surgery showed soft tissue thickening on the left frontozygomatic suture (Fig. 1B). The patient had secondary surgery for the exploration and removal of the mass. The resected mass contained chronic inflammatory tissue with a grainy, cloudy liquid, and no gross evidence of a plate or screws inside the mass (Fig. 1C, D). However, the histological findings of the mass revealed the fine fragments of a foreign body with inflammatory cell infiltration, which was diagnosed as a foreign body granuloma (Fig. 1E).

\section{Case 2 (patient no. 2)}

A 28-year-old man was struck on the right side of the face while snowboarding. The patient had a right zygomaticomaxillary complex fracture, which was fixed with the Inion CPS 2.0-mm 4-hole bioabsorbable plate on the frontozygomatic suture, a 1.5$\mathrm{mm} \mathrm{C}$-shaped 7-hole plate on the infraorbital rim, and a bioabsorbable mesh plate on the anterior wall of the maxilla. The patient visited our outpatient clinic 17 months later complaining of a palpable mass, measuring $3 \mathrm{~cm} \times 2 \mathrm{~cm}$, on the left frontozygomatic suture (Fig. 2A). The mass was a painless, visible, fixed mass. A CT scan showed a high-density content mass on the right frontozygomatic suture (Fig. 2B). The patient underwent secondary surgery for the exploration and removal of the mass. The bioabsorbable plate and screws had been replaced by a fibrous capsule, which contained a yellow, cloudy fluid and the remnants of the incompletely degraded bioabsorbable plate and screws (Fig. 2C). The histological findings of the mass showed a foreign body reaction with fibrosis (Fig. 2D). 


\section{Fig. 1. Case 1 (patient no. 1)}

(A) Preoperative clinical view 29 months after Rapidsorb plate fixation. (B) Computed tomography scan shows soft tissue thickening on the left frontozygomatic suture (red circle). (C) Fibrous encapsulated mass. (D) Resected mass containing inflammatory tissue with a yellow, cloudy liquid. (E) Fine foreign body fragments, multinucleated giant cells, lymphocytes, and histiocytes are seen $\left(H \& E_{1} \times 100\right)$.
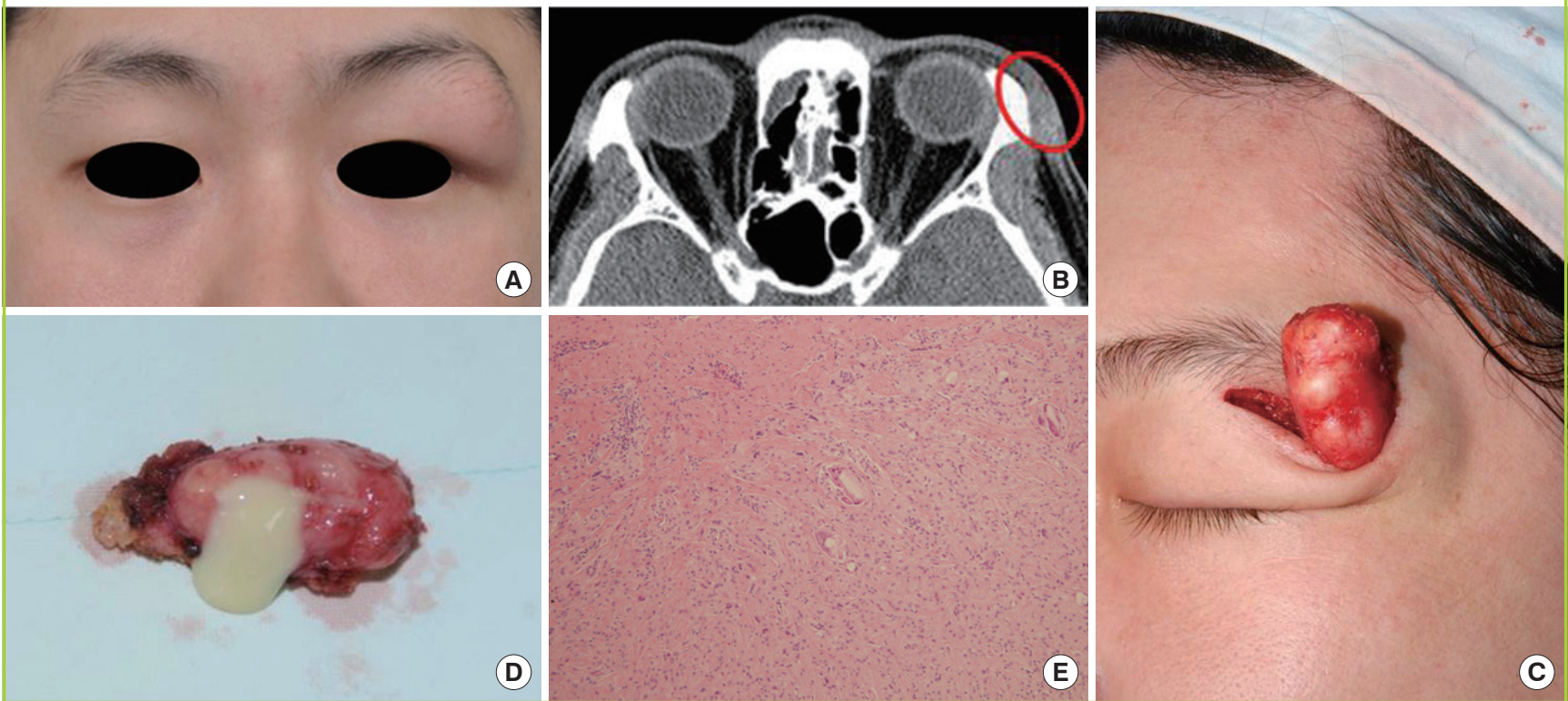

\section{Fig. 2. Case 2 (patient no. 2)}
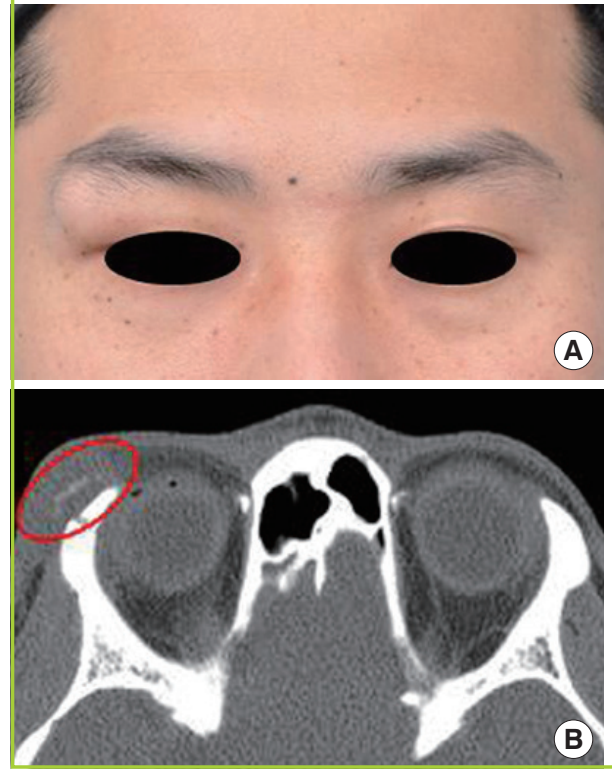
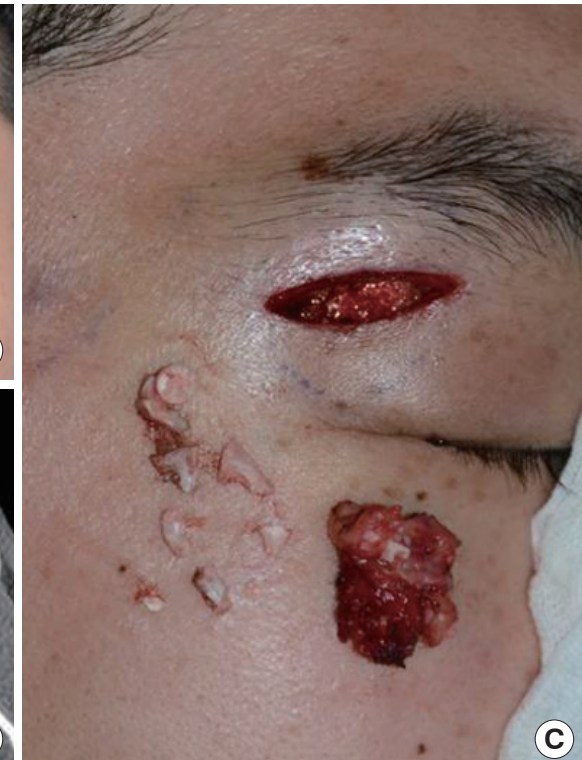

(A) Preoperative clinical view 17 months after Inion CPS plate fixation. (B) Computed tomography scan showing high-density content with soft tissue thickening on the right frontozygomatic suture (red circle). (C) Resected mass containing a yellow, cloudy fluid and the remnants of an incompletely degraded bioabsorbable plate and screws. (D) Foreign body material with multinucleated giant cells, fibroblasts, lymphocytes, and histiocytes $\left(H \& E_{1} \times 100\right)$.

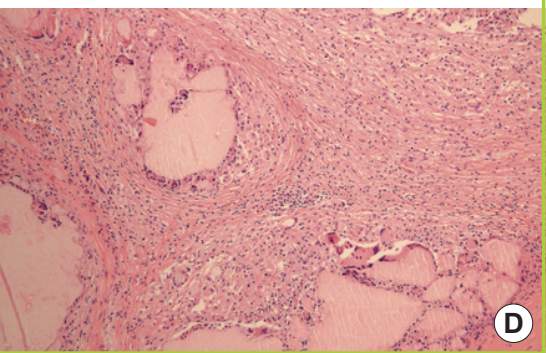

\section{Case 3 (patient no. 4)}

A 56-year-old man visited our clinic to receive treatment for a mass on the right frontozygomatic suture and infraorbital rim (Fig. 3A). He had fallen while driving a concrete mixer truck 25 months earlier. The patient had a right zygomaticomaxillary complex fracture, which was fixed with the Inion CPS 2.0-mm 4-hole plate on the frontozygomatic suture and the 1.5-mm 6-hole plate on the infraorbital rim. He suffered from two palpable, fixed masses, measuring $2.5 \mathrm{~cm} \times 1 \mathrm{~cm}$ each, for 4 months. A CT scan showed soft tissue thickening on the right frontozygomatic suture and infraorbital rim (Fig. 3B, C). The patient underwent secondary surgery for the exploration and removal of the mass. The mass contained fibrous tissue with a yellow, cloudy fluid and the remnants of the incompletely degraded bioabsorbable plate and screws (Fig. 3D, E). The histological findings of the mass demonstrated a foreign body reaction with fibrosis (Fig. 3F). 


\section{Fig. 3. Case 3 (patient no. 4)}

(A) Preoperative clinical view 25 months after Inion CPS plate fixation. (B) Computed tomography scan shows soft tissue thickening on the right frontozygomatic suture (red circle). (C) Soft tissue thickening on the right infraorbital rim (red circle). (D) Resected mass containing a yellow, cloudy fluid and remnants of an incompletely degraded bioabsorbable plate and screws on the right frontozygomatic suture. (E) Resected mass on the right infraorbital rim. (F) Foreign body material with multinucleated giant cells, fibroblasts, lymphocytes, and histiocytes (H\&E, $\times 200)$.
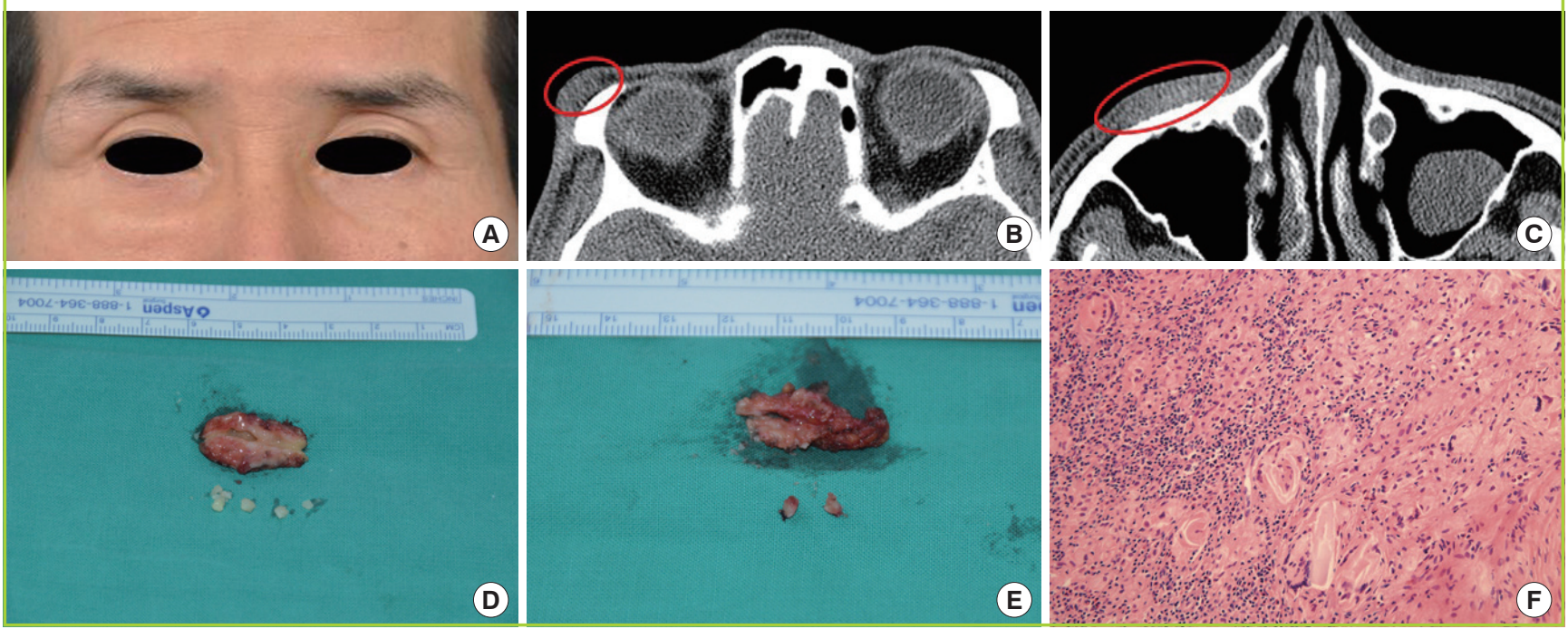

\section{DISCUSSION}

Bioabsorbable plates ideally provide rigid fixation during the initial bone healing phase and are degraded by the body after osteosynthesis. In addition, these plates must be biocompatible with the recipient environment to prevent a significant inflammatory foreign body reaction $[5,6]$. Multiple factors, such as the chemical composition, size, and shape of bioabsorbable plates, affect the occurrence of foreign body reactions [8]. The results of several studies reveal that the foreign body reaction of a bioabsorbable plate results from an inadequate degradation of the chemical components of the plate. PGA and PLA are popular among several chemical compositions for bioabsorbable plates, and PLA exists in two different isomeric configurations of poly-L-lactic acid (PLLA) and poly-DL-lactic acid (PDLLA) [5,8]. PGA and PLA biodegradation occurs in a two-stage process. The first stage relies on the hydrolysis of the polymer's chemical bonds, thereby creating a shorter-chain molecule. The presence of these small polymer fragments can evoke a foreign body reaction. Then, they are phagocytized by macrophages and carried to the liver for metabolism. In the second metabolic phase, the breakdown products are metabolized to $\mathrm{CO}_{2}$ and $\mathrm{H}_{2} \mathrm{O}[5,6,8,10,14]$. Secondary surgery for removal can be avoided through this process. Degradation properties and rates differ according to the main chemical components because they depend on the crystallinity and hydrophobicity of the polymers. PGA is a hard crystalline polymer and is less hydrophobic, so it undergoes rapid breakdown within 1 year. In contrast, PLA is a semicrystalline polymer and is highly hydrophobic, so it is degraded much more slowly within 5-6 years. Therefore, PGA is typically used in conjunction with PLA to create better strength and degradation profiles than those of either of the homopolymers alone $[8,10,11]$. The Rapidsorb plate is manufactured from 85:15 poly (L-lactide-co-glycolide, PLGA). This copolymer is formed by combining PLLA and PGA. These plates maintain approximately $85 \%$ of their initial strength after 8 weeks and are completely absorbed after 1 year [15]. The Inion CPS plate is a copolymer of PLLA, PLDLA, and trimethylene carbonate. These plates are absorbed slowly, retaining $70 \%$ of their initial strength at 9 weeks, and they are completely degraded in 2-4 years [16].

In this study, six patients had palpable, visible masses and two patients had focal swelling around the bioabsorbable plates and screws. No risk factors of a foreign body reaction, namely gender and material type, could be found (Table 3). Most of the complications occurred in the frontozygomatic suture, which was fixed with a large-volume, 2.0-mm-thick bioabsorbable plate and 7-mm screws. As the implant materials have high volume and thickness, dead space may form and lead to fluid collection and a foreign body reaction [17]. In addition, this complication is caused by inadequate degradation, as degradation properties and rates are influenced by implant volume, geometrical shape, and chemical composition [18]. In contrast, there was no complication in the anterior wall of the maxilla. We think that this can be attributed to the small-volume implant, 1.5-mm mesh plate, and 4-mm screws used for fixation; further, the small polymer fragments derived from the first degradation 
process were partially absorbed into the maxillary sinus without a foreign body reaction.

The resected masses of six patients were diagnosed as foreign body reactions with fibrosis $(n=5)$ and a foreign body granuloma $(n=1)$. The patient with a foreign body granuloma was fixed with a 2.0-mm Rapidsorb plate. No gross evidence of a plate or screws was detected inside the granuloma, but fine foreign body fragments with inflammatory cell infiltration were seen histologically. This finding occurred because the Rapidsorb plate was almost absorbed 29 months after surgery. Two patients who were under observation without surgery continue to be monitored. Their symptoms improved to some degree, but mild focal swelling remains 6 years after surgery.

Plate degradation properties and rates change depending on the characteristics of the bioabsorbable plates, such as chemical composition and implant volume. Inadequate degradation can cause a delayed foreign body reaction with inflammation, thus requiring a second exploratory operation. In addition, a palpable mass or focal swelling resulting from a foreign body reaction can remain for years. Therefore, it is prudent to consider delayed complications when using bioabsorbable plates, and surgeons should conduct longer and closer follow-ups.

\section{REFERENCES}

1. Bergsma JE, de Bruijn WC, Rozema FR, et al. Late degradation tissue response to poly(L-lactide) bone plates and screws. Biomaterials 1995;16:25-31.

2. Rubin JP, Yaremchuk MJ. Complications and toxicities of implantable biomaterials used in facial reconstructive and aesthetic surgery: a comprehensive review of the literature. Plast Reconstr Surg 1997;100:1336-53.

3. Orringer JS, Barcelona V, Buchman SR. Reasons for removal of rigid internal fixation devices in craniofacial surgery. $\mathrm{J}$ Craniofac Surg 1998;9:40-4.

4. Wiltfang J, Merten HA, Schultze-Mosgau S, et al. Biodegradable miniplates (LactoSorb): long-term results in infant minipigs and clinical results. J Craniofac Surg 2000;11:239-43.

5. Imola MJ, Hamlar DD, Shao W, et al. Resorbable plate fixation in pediatric craniofacial surgery: long-term outcome. Arch Facial Plast Surg 2001;3:79-90.

6. Mackool R, Yim J, McCarthy JG. Delayed degradation in a resorbable plating system. J Craniofac Surg 2006;17:194-7.

7. Katsuragi YT, Gomi A, Sunaga A, et al. Intracerebral foreign body granuloma caused by a resorbable plate with passive intraosseous translocation after cranioplasty. J Neurosurg Pediatr 2013;12:622-5.

8. Xue AS, Koshy JC, Weathers WM, et al. Local foreign-body reaction to commercial biodegradable implants: an in vivo animal study. Craniomaxillofac Trauma Reconstr 2014;7:27-34.

9. Bell RB, Kindsfater CS. The use of biodegradable plates and screws to stabilize facial fractures. J Oral Maxillofac Surg 2006;64:31-9.

10. Pietrzak WS, Sarver DR, Verstynen ML. Bioabsorbable polymer science for the practicing surgeon. J Craniofac Surg 1997;8:87-91.

11. Eppley BL, Morales L, Wood R, et al. Resorbable PLLAPGA plate and screw fixation in pediatric craniofacial surgery: clinical experience in 1883 patients. Plast Reconstr Surg 2004;114:850-6.

12. Kwon H, Kim SW, Jung SN, et al. Cellulitis related to bioabsorbable plate and screws in infraorbital rim fracture. J Craniofac Surg 2011;22:625-7.

13. Kumar AV, Staffenberg DA, Petronio JA, et al. Bioabsorbable plates and screws in pediatric craniofacial surgery: a review of 22 cases. J Craniofac Surg 1997;8:97-9.

14. Bergsma EJ, Rozema FR, Bos RR, et al. Foreign body reactions to resorbable poly(L-lactide) bone plates and screws used for the fixation of unstable zygomatic fractures. J Oral Maxillofac Surg 1993;51:666-70.

15. Miller RA, Brady JM, Cutright DE. Degradation rates of oral resorbable implants (polylactates and polyglycolates): rate modification with changes in PLA/PGA copolymer ratios. J Biomed Mater Res 1977;11:711-9.

16. Laughlin RM, Block MS, Wilk R, et al. Resorbable plates for the fixation of mandibular fractures: a prospective study. J Oral Maxillofac Surg 2007;65:89-96.

17. Rha EY, Paik H, Byeon JH. Bioabsorbable plates and screws fixation in mandible fractures: clinical retrospective research during a 10-year period. Ann Plast Surg 2015;74:432-6.

18. Sevastjanova NA, Mansurova LA, Dombrovska LE, et al. Biochemical characterization of connective tissue reaction to synthetic polymer implants. Biomaterials 1987;8:242-7. 